\title{
A Descriptive Study about Self Assessment on Competencies for Caring of Dying Patients among Nursing Students after Experiencing a Patient Death
}

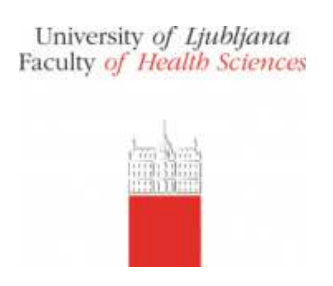

\section{Background}

Caring for dying patients is one of the most stressful and traumatic experiences reported by the nursing students.

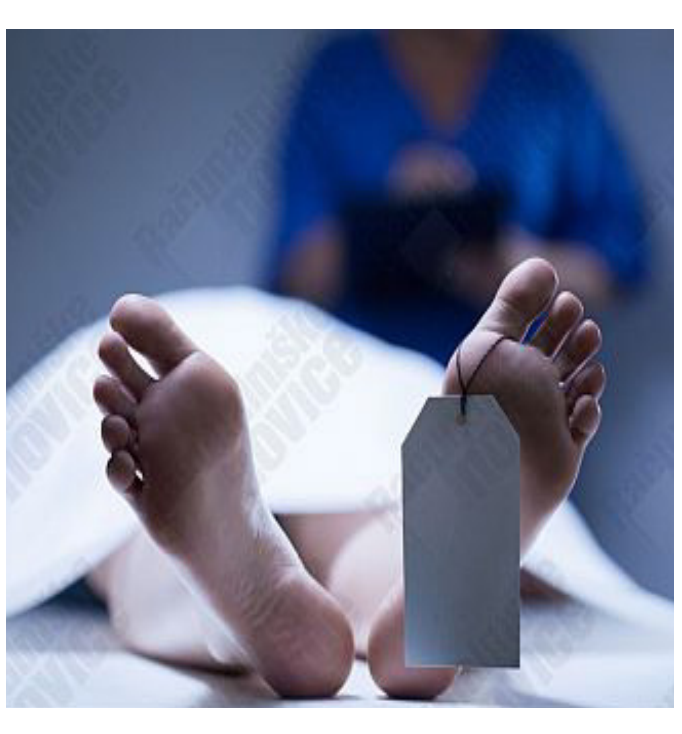

Palliative and hospice care

requires adequate knowledge and competencies acquired through formal education and practical training. Preregistration nursing curricula have traditionally had a limited emphasis on dying and death and nursing students report feeling unprepared to care for dying patients.

\section{Aims}

The aim of the study was to identify to what extent the nursing students' background experience towards death and dying influence their competency self-assessment and their need for support of clinical and school mentors when providing care at the end of life.

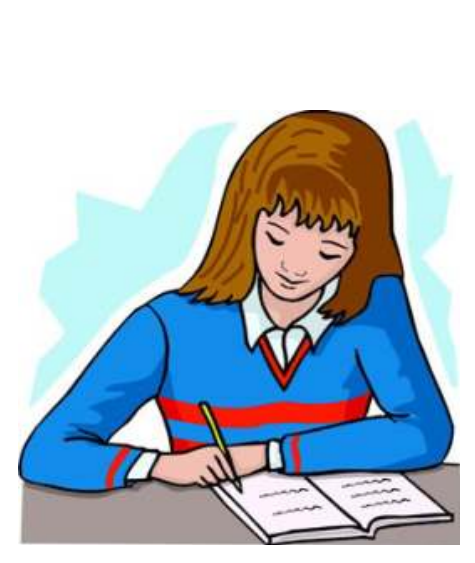

\section{Methods}

For this study, a qualitative research method was used with a sample of 38 (32\%) second study-year nursing students (Table 1). Data were collected in 2014/2015. The nursing students' written descriptions of their experiences and competencies were analyzed using Colaizzi's seven step procedure.

Table 1: Sociodemographical and personal characteristics of the nursing students

\begin{tabular}{llr}
\multirow{2}{*}{ Sociodemographical and personal characteristics } & N \\
\multirow{3}{*}{ Gender } & female & 30 \\
\cline { 2 - 3 } & male & 8 \\
\multirow{2}{*}{ Age } & 19 to 24 years & 27 \\
\cline { 2 - 3 } & 25 to 30 years & 7 \\
\hline \multirow{3}{*}{ Education } & secondary health school & 4 \\
\cline { 2 - 3 } & high school & 24 \\
\hline \multirow{2}{*}{ Religiosity } & others & 8 \\
\cline { 2 - 3 } & yes & 21 \\
\hline
\end{tabular}

\section{Results}

All of the nursing students (38) have already cared for the dying patients or witnessed death. Four themes emerged from this analysis:

1. experienced with many negative emotions: fear, frustration, anger, sadness, disappointment, anxiety. They reported that this experience was highly stressful mainly due to the lack of information or because it was their first encountering with death and dying;

2. contemplation of the patient's dignity. The nursing students provided care to the terminally ill patients but did not recognize the signs of approaching death. They rarely performed personal care after death or they refused the request to do that;

3. feeling unprepared, helpless for providing physical, emotional, social and spiritual support for dying patients. Only a small number $(13 / 38)$ of the participants believe that they are professionally competent to the nursing care at the end of life. All the participants acknowledged their insufficient communicative and organizational skills;

4. needs for debriefing strategies with school and clinical mentors. The mentors should offer the nursing students their constant, understanding support and counseling, drawn from their own life experiences.

\section{Conclusions}

Palliative care and end of life care is an essential component of nursing education which should be based on experiential education. In clinical training, the care for palliative and dying patients should be introduced gradually and always supported and monitored by the school and clinical mentors.

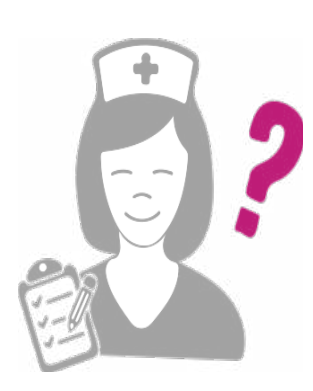

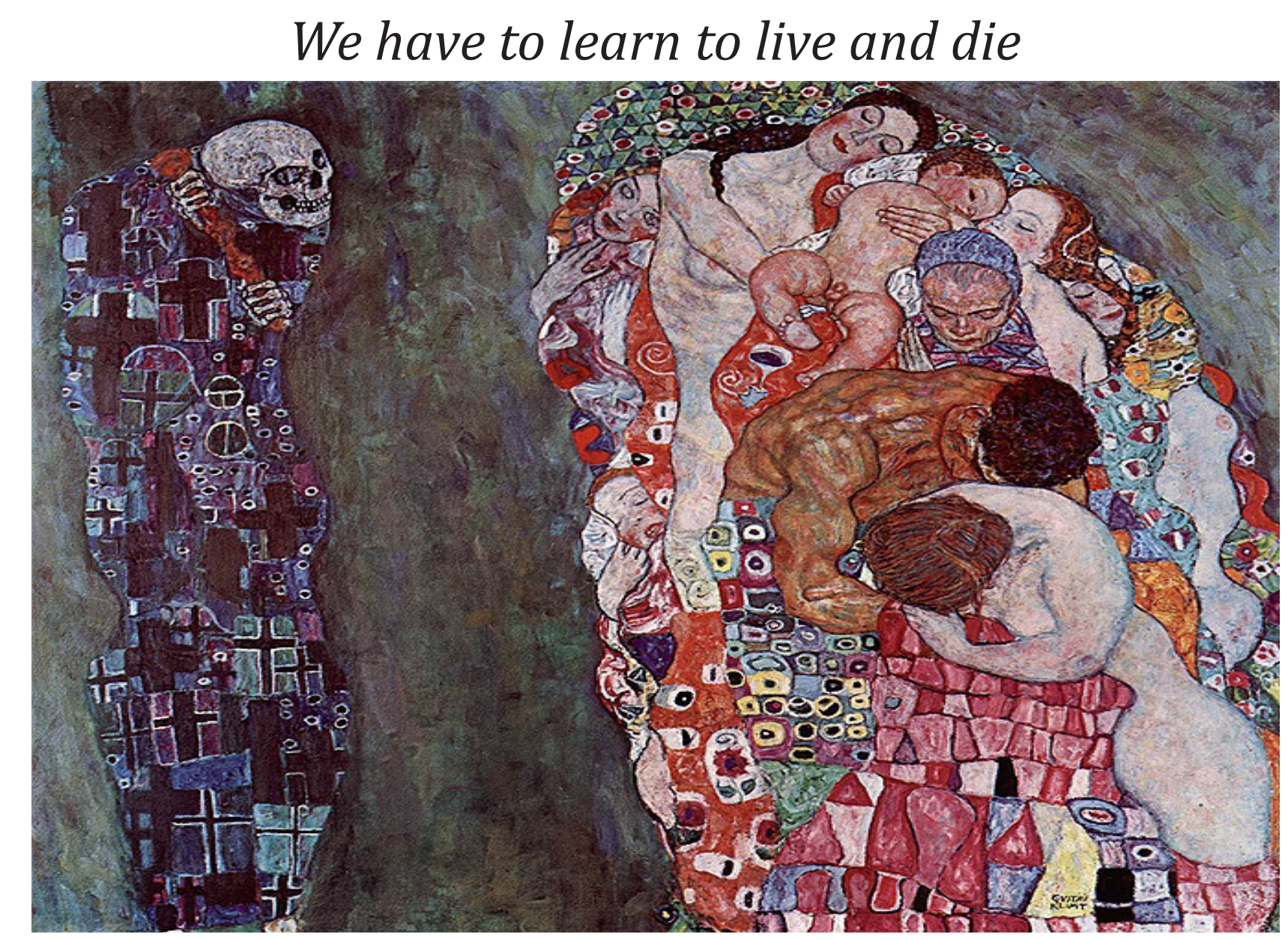

